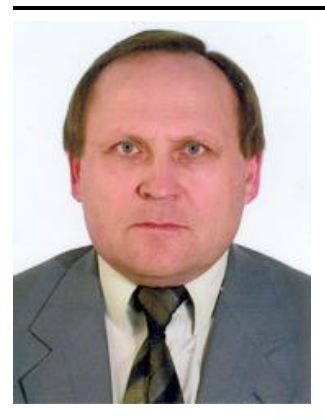

УДК 330.111.62:339.13:631.145

https://doi.org/10.47612/978-985-7149-55-1-2020-34-37

Николай Бычков, кандидат экономических наук, доцент, заведующий сектором имущественных отношений и приватизации Институт системных исследований в АПК НАН Беларуси, г. Минск

\title{
К вопросу разгосударствления и приватизации в сельском хозяйстве Республики Беларусь
}

В сельском хозяйстве по состоянию на 1 января 2020 г. финансовые обязательства субъектов хозяйствования превышают выручку от реализации продукции, товаров, работ и услуг на 1,6 млрд руб. Доля убыточных сельскохозяйственных организаций в общей численности за последние семь лет возросла с 13,0 до 16,5 \% [1]. В сложившейся ситуации ведущее место занимает государственный сектор сельского хозяйства. В узком смысле (вариант 1) это совокупность предприятий, где имущество находится в собственности государства и передано на праве хозяйственного ведения унитарным предприятиям, в широком смысле (вариант 2) в состав госсектора дополнительно включены объекты с долей участия государства в уставных фондах в размере не менее $25 \%$. Здесь имущество находится в собственности хозяйственных обществ, а управление регламентируется долей государства в уставном фонде с точки зрения принятия решений.

Более $30 \%$ субъектов государственного сектора находится в сложном экономическом положении. Здесь сосредоточена третья часть земельных, трудовых ресурсов, основных фондов. В данной группе предприятий параметры продуктивности продукции земледелия и животноводства ниже на 10-20 \%, чем в среднем по отрасли, отмечается отрицательная доходность, кредиторская задолженность, задолженность по кредитам и займам превышает выручку от реализации продукции.

В контексте реализации указов Президента Республики Беларусь от 4 июля 2016 г. № 253 «О мерах по финансовому оздоровлению сельскохозяйственных организаций» [2], от 2 октября 2018 г. № 399 «О финансовом оздоровлении сельскохозяйственных организаций» [3], от 25 февраля 2020 г. № 70 «О развитии агропромышленного комплекса Витебской области» [4], постановления Совета Министров Республики Беларусь от 18 марта 2019 г. № 167 «О мерах по реализации Указа Президента Республики Беларусь от 2 октября 2018 г. № 399» [5] организационно-экономическими мерами финансового оздоровления и реформирования по состоянию 1 августа 2020 г. пользуются 439 сельскохозяйственных организаций, или $32 \%$ общей численности. Это на $4 \%$ больше, чем четыре года назад.

В качестве дополнительных организационно-экономических мер повышения эффективности работы организации используют ряд инструментов:

- 64 сельскохозяйственные организации - реорганизованы путем присоединения к иным коммерческим организациям;
- 18 организаций - полномочия исполнительного органа (руководителя) сельскохозяйственной организации по договору переданы другой коммерческой организации;

- 13 организаций - изменены контрактные отношения с руководителями в части безвозмездной передачи в собственность не более $25,01 \%$ акций уставного фонда хозяйственного общества при условии обеспечения эффективной хозяйственной деятельности организации (отсутствие убытков, просроченных обязательств и восстановление платежеспособности) по истечении пятилетнего периода реализации бизнес-плана оздоровления;

- 1 организация - использован механизм замещения активов в процедуре санации;

- 2 организации - проведена процедура конвертации требований кредиторов в акции хозяйственных обществ;

- 5 организаций - проданы как имущественные комплексы, в том числе 2 - иностранному инвестору ООО «Белагрия» (словацкий фермерский кооператив), 1 К(Ф)Х «Новицких», 1 - К(Ф)Х «Опыт КАА», 1 - ОАО «Смолевичи Бройлер». Цена продажи - от одной базовой величины до $20 \%$ стоимости чистых активов, рыночной стоимости. Условия продажи - сохранение рабочих мест, внесение инвестиций в производство в размере 16 млн руб.;

- 28 организаций - находятся в перечне оказания спонсорской помощи;

- 38 организациям предоставлены целевые бюджетные займы на завершение строительства МТФ;

- 57 организаций - включены в состав 7 сырьевых зон агропромышленного комплекса Витебской области.

В отношении группы организаций, находящихся в антикризисном управлении (102 объекта), произошли следующие структурные изменения: 20,6 \% организаций ликвидированы и 4,9 - находятся в стадии ликвидации; 2,0 - проданы как имущественные комплексы; 8,8 - дело о банкротстве прекращено в связи с заключением мирового соглашения; 2,9 - отказано в возбуждении конкурсного производства и организации включены в перечень досудебного оздоровления по Указу № 399; 60,8 \% организаций- введена процедура санации.

В соответствии с установленными критериями платежеспособности, ее восстановили в процедуре досудебного оздоровления более $50 \%$ объектов. Вместе с тем, несмотря на принятые организационно-экономические меры, обращает на себя внимание отсутствие на практике использования таких инструментов, как сдача 
предприятий в аренду с последующим правом выкупа индивидуальным предпринимателям, юридическим лицам; передача юридическим лицам, индивидуальным предпринимателям в доверительное управление государственного пакета акций с последующим правом выкупа. В республике отсутствует нормативный акт по технологии дополнительной мотивации менеджмента организаций путем безвозмездной передачи части государственного пакета акций в собственность по результатам выполнения бизнес-плана финансового оздоровления и др. Основная причина - отсутствие надлежащей идеологии территориальных органов власти, а также возникшая необходимость совершенствования методологии осуществления этих процессов в соответствии с утвержденными на местах положениями, инструкциями местных Советов депутатов.

В качестве совершенствования механизма разгосударствления и повышения эффективности управления убыточными, устойчиво неплатежеспособными организациями предлагаются следующие меры.

1. В случае сдачи предприятий новым пользователям в аренду с последующим правом выкупа:

- для группы предприятий, имеющих устойчивую неплатежеспособность, если показатель обеспеченности финансовых обязательств активами неплатежеспособной организации превышает установленный норматив $\left(K_{3} \geq 0,85\right)$, арендную плату за имущественный комплекс следует устанавливать в размере 1 базовой величины в год на период реализации бизнес-плана финансового оздоровления;

- для группы предприятий, где неплатежеспособность приобретает устойчивый характер и $\mathrm{K}_{3}$ равен 0,85-0,5, годовая арендная плата за пользование предприятием в целом как имущественным комплексом устанавливается из расчета $2 \%$ балансовой стоимости имущества;

- для группы предприятий, где неплатежеспособность приобретает устойчивый характер и $\mathrm{K}_{3}<0,5$, годовая арендная плата за пользование предприятием в целом как имущественным комплексом устанавливается из расчета $5 \%$ балансовой стоимости имущества.

Наряду с этим предлагается интегрированный вариант, когда годовая сумма арендных платежей определяется в размере до 5 \% балансовой стоимости передаваемых в аренду основных средств, но не ниже суммы амортизационных отчислений. Стоимость оборотных средств передается претенденту (индивидуальному предпринимателю, юридическому лицу) безвозмездно с возвратом по окончании срока аренды в оценке по твердой валюте на момент заключения договора либо в выкуп (в рассрочку, в течение 3-5 лет). Земельный участок для ведения товарного сельского хозяйства передается претенденту на тех же условиях, что и у арендодателя. В случае передачи земельного участка претенденту в аренду регулирование земельных отношений осуществляется отдельно по договору аренды в соответствии с законодательством.

В рамках расширения прав местных исполнительных и распорядительных органов, местных Советов депутатов в части регулирования имущественных отношений предлагаются в зависимости от финансового результата от реализации продукции (работ, услуг) на момент включения арендодателя в перечень организаций, подлежащих оздоровлению, подходы, представленные на рисунке.

2. Альтернативным вариантом аренды предприятия как имущественного комплекса убыточной, неплатежеспособной организации может выступать лизинг предприятия. Это многофункциональный и гибкий инструмент, который одновременно обладает чертами различных имущественных отношений: кредитования, аренды, аренды с правом выкупа, доверительного управления. Его реализация предполагает соответствующее нормативное сопровождение.

3. Продажу имущества (акций), имущественных комплексов убыточных неплатежеспособных сельскохозяйственных организаций рекомендуется проводить по показателю «чистые активы». Это повысит инвестиционные предложения стратегических инвесторов. Цена продажи предприятий, где чистые активы равны нулю либо имеют отрицательное значение, должна устанавливаться по «нулевой» ставке при условии реализации инвестиционного проекта.

Начальная цена акций должна устанавливаться по номинальной стоимости на дату принятия решения о проведении аукциона (конкурса) без индексации на индекс изменения стоимости средств материально-технического назначения при условии выполнения установленных требований (подготовка и переподготовка персонала, сохранение профиля деятельности организации, создание новых рабочих мест и др.).

4. Минимальный размер государственного пакета акций, передаваемый в доверительное управление управляющей организации (управляющему), должен составлять не менее $25,01 \%$ уставного фонда, что позволит доверительному управляющему проводить блокировку неэффективных решений общего собрания акционеров по вопросам внесения изменений и (или) дополнений в устав, увеличения или уменьшения его уставного фонда, реорганизации и ликвидации, приобретения обществом размещенных им акций по решению самого общества, утверждения локальных нормативных правовых актов, о совершении крупной сделки, предметом которой является имущество стоимостью от $50 \%$ балансовой стоимости активов ОАО, и иным вопросам, по которым принятие решений большинством (не менее трех четвертей) голосов участников собрания предусмотрено уставом. Данная модель упраздняет не оправдавший себя на практике институт владельческого надзора в хозяйственных обществах.

5. Передача полномочий исполнительного органа убыточной, неплатежеспособной сельскохозяйственной организации по договору индивидуальному предпринимателю, в том числе с последующим правом выкупа, должна проводиться на конкурсной основе с учетом положительного опыта предпринимательской и управленческой деятельности, наличия инвестиционного капитала по схеме (проект + собственный источник финансирования). 


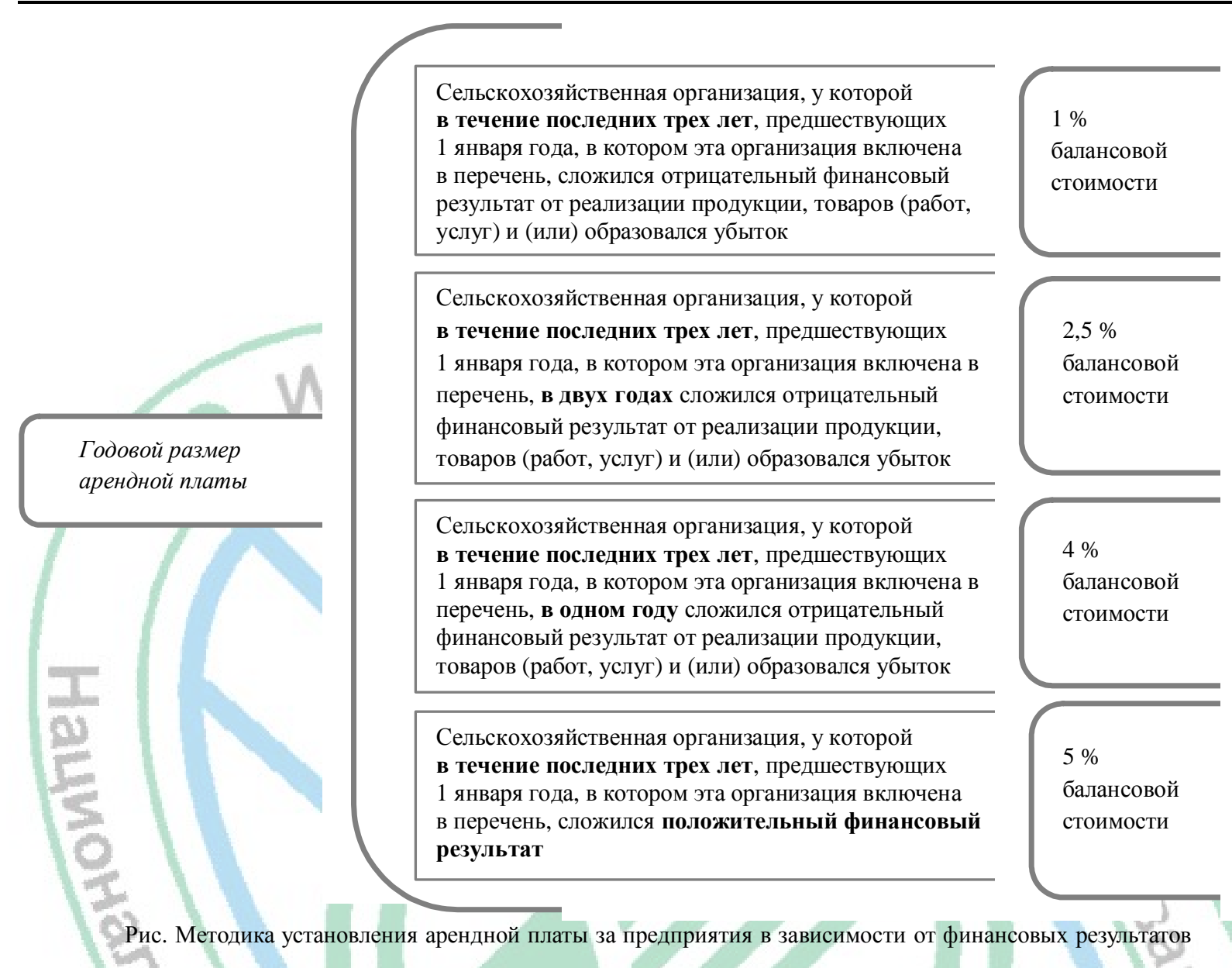

6. Передача в собственность руководителя убыточной, неплатежеспособной организации не более $25,01 \%$ акций в уставном фонде хозяйственного общества в соответствии с трудовым договором (контрактом) должна проводиться по результатам выполнения бизнес-плана финансового оздоровления при условии эффективной хозяйственной (экономической) деятельности, отсутствия убытков, восстановления коэффициентов платежеспособности не ниже нормативного значения, и одновременно коэффициент отночения просроченных обязательств (долгосрочных и краткосрочных) к среднемесячной выручке должен составлять $<1$.

7. Введение института антикризисного управления применительно к сельскому хозяйству должно учитывать следующие специфические особенности:

сельскохозяйственное производство связано с использованием естественных биологических процессов. Отсюда срок санации следует увеличить с 36 месяцев до 5 лет. Продление срока санации должно находиться в компетенции экономического суда и дополнительно продляться в случае необходимости сроком на 24 месяца;

к числу несостоятельных организаций, следует относить объекты, которые не способны исполнить просроченные обязательства в течение 12-16 месяцев со дня наступления установленного срока для их исполнения. В отношении данной группы организаций целесообразно применять меры ликвидационного производства; для целей принятия решений по реформированию организаций в антикризисном управлении целесообразно дополнительно использовать показатель платежеспособности - коэффициент отношения просроченных обязательств (долгосрочных и краткосрочных) к среднемесячной выручке. При значении показателя за отчетный период $\geq 5$ возникают основания для изменения имущественных отношений;

введение механизма несостоятельности требует подготовки специалистов по антикризисному управлению с учетом специфики ведения агропромышленного производства. Личность управляющего имеет ключевое значение. От того, как он построит отношения с кредиторами, в том числе межличностные, во многом зависит результативность санации. В связи с этим важное значение приобретает вопрос доверия кредиторов. Только в случае, если кредиторы доверяют управляющему, они будут готовы какое-то время ждать возвращения задолженности. В этом смысле можно говорить о наличии фидуциарного элемента во взаимоотношениях между кредиторами и управляющим. Отсутствие доверия порождает многочисленные жалобы кредиторов на действия (бездействие) управляющего и порой судебные разбирательства. Это, в свою очередь, ведет к потере времени и ставит под угрозу выполнение любого, даже самого перспективного плана санации.

8. Применение модели замещения активов сельскохозяйственной организации в процедуре санации позволит новым юридическим лицам организовать 
производство с чистого финансового листа; сократить требования кредиторов путем передачи лизинговых обязательств новой организации пропорционально переданному имуществу; уменьшить расходы (убытки) на ведение текущей сельскохозяйственной деятельности путем оптимизации затрат; увеличить процент погашения требований кредиторов в денежной форме, а также путем замещения требования активами (акциями) до $100 \%$; в кратчайшие сроки осуществить продажу имущества в порядке, предусмотренном планом санации, и направить вырученные средства на погашения требований кредиторов, после вынесения решения о ликвидации организации - предложить нереализованное имущество кредиторам в счет погашения долгов.

Таким образом, реализация комплекса организационно-экономических и технико-технологических мер будет играть определяющую роль в укреплении государственного сектора экономики в сельском хозяйстве, его структурной трансформации, направленной, в частности, на дальнейшее преобразование организаций, находящихся в сложном экономическом положении. Это предполагает привлечение эффективных собственников (инвесторов), избавление от паллиативных государственных активов и фактически неуправляемых неликвидов.

На наш взгляд, в краткосрочном периоде целесообразно осуществление следующих мер:

1) сокращение прямого участия государства в экономике убыточных, устойчиво неплатежеспособных организаций, прежде всего путем последовательной реализации принципа «презумпции полезности» разгосударствления, гарантии долгосрочности механизмов с участием индивидуальных предпринимателей, коммерческих организаций, априорная подготовка поля смены собственника;

2) оптимизация госсектора от «непрофильных» и неэффективных активов: упрощенный порядок продажи низколиквидных активов, несостоятельных предприятий как имущественных комплексов и др.;

3) повышение качества государственного управления в организациях с госучастием, что не должно сводиться только к модификации корпоративного управления: сюда должна включаться и систематизация интересов государства в стратегическом ядре государственного сектора сельского хозяйства. Все сохраняемые в ядре государственные организации либо с участием государства в уставных фондах не менее $25 \%$ должны обеспечить биржевые котировки акций и стать публичными;
4) синхронизация республиканской и региональной политики разгосударствления, транслирование презумпции качественного преобразования с участием отечественных и зарубежных инвесторов на уровне субъектов хозяйствования и государственного контроля за их исполнением.

В долгосрочном периоде нами рекомендуются следующие меры:

1) развитие инструментов финансового рынка, стимулирование участия институциональных инвесторов;

2) максимизация вовлечения в коммерческий оборот неиспользуемого недвижимого государственного имущества: упрощение процедур, заявительная продажа на электронных торгах по цене, предлагаемой рынком;

3) привлечение частных инвестиций в социальную сферу и на рынки услуг, в том числе путем развития государственно-частного партнерства.

\section{Список использованных источников}

1. Сельское хозяйство Республики Беларусь, 2020 : стат. сб. / Нац. стат. ком. Респ. Беларусь. - Минск, 2020. $178 \mathrm{c}$.

2. О мерах по финансовому оздоровлению сельскохозяйственных организаций [Электронный ресурс] : Указ Президента Респ. Беларусь, 4 июля 2016 г., № 253 // КонсультантПлюс: Беларусь. Версия 4016.00.07 / ООО «ЮрСпектр», Нац. центр правовой информ. Респ. Беларусь. - Минск, 2020.

3. О финансовом оздоровлении сельскохозяйственных организаций [Электронный ресурс] : Указ Президента Респ. Беларусь, 2 окт. 2018 г., № 399 // КонсультантПлюс: Беларусь. Версия 4016.00.07 / ООО «ЮрСпектр», Нац. центр правовой информ. Респ. Беларусь. - Минск, 2020.

4. О развитии агропромышленного производства Витебской области [Электронный ресурс] : Указ Президента Респ. Беларусь, 25 февр. 2020 г., № 70 // КонсультантПлюс: Беларусь. Версия 4016.00.07 / ООО «ЮрСпектр», Нац. центр правовой информ. Респ. Беларусь. Минск, 2020.

5. О мерах по реализации Указа Президента Республики Беларусь от 2 октября 2018 г. № 399 [Электронный ресурс] : постановление Совета Министров Респ. Беларусь, 18 марта 2019 г., № 167 // КонсультантПлюс: Беларусь. Версия 4016.00.07 / ООО «ЮрСпектр», Нац. центр правовой информ. Респ. Беларусь. - Минск, 2020.
(Материал поступил 16.10.2020 2. 